\title{
Distance to school is associated with sedentary time in children: findings from the URBAN study
}

\section{Erica A. Hinckson ${ }^{1}$ *, Les McGrath ${ }^{1}$, Will Hopkins ${ }^{2}$, Melody Oliver ${ }^{3}$, Hannah Badland ${ }^{4}$, Suzanne Mavoa ${ }^{4,5}$, Karen Witten ${ }^{5}$ and Robin A. Kearns ${ }^{6}$}

${ }^{1}$ Faculty of Health and Environmental Sciences, Auckland University of Technology, Auckland, New Zealand

${ }^{2}$ Faculty of Health and Environmental Sciences, Sport Performance Research Institute New Zealand, Auckland University of Technology, Auckland, New Zealand

${ }^{3}$ Faculty of Health and Environmental Sciences, Human Potential Centre, Auckland University of Technology, Auckland, New Zealand

${ }^{4}$ Faculty of Medicine, Dentistry and Health Science, McCaughey VicHealth Centre for Community Wellbeing, Melbourne School of Population and Global Health, University of Melbourne, Melbourne, VIC, Australia

${ }^{5}$ Social and Health Outcomes Research and Evaluation (SHORE) and Whariki Research Centre, Massey University, Auckland, New Zealand

${ }^{6}$ School of Environment, The University of Auckland, Auckland, New Zealand

\section{Edited by:}

Gerry Leisman, ORT Braude College of Engineering, Israel

Reviewed by:

Michal Katz-Leurer, Tel Aviv University, Israel

Sallie Greenwood, Waikato Institute

of Technology, New Zealand

*Correspondence:

Erica A. Hinckson, Faculty of Health and Environmental Sciences,

Auckland University of Technology,

Private Bag 92006, Auckland,

New Zealand

e-mail: erica.hinckson@aut.ac.nz
Sedentary behavior is associated with overweight and obesity in children, and distance to school has been negatively associated with active commuting to school. It is not known how distance to school relates to sedentary behavior in children. The aim of this study was to investigate the association between distance to school and children's sedentary behavior during weekdays at times where children interact with the neighborhood environment. Children (5-13 years, $n=295)$ who participated in the understanding relationships between activity and neighborhoods study (2008-2010) across four New Zealand cities wore a hip-mounted accelerometer for 7 days. Minutes spent sedentary (accelerometer count $<100 \mathrm{~min}^{-1}$ ) were derived for the school travel periods (0800-0859 and 1500-1559) and after school discretionary time (1600-1759). Shortest street network distance to school was calculated from residential addresses using geographical information systems and parsed into tertiles for analysis. Children completed a daily travel log including mode of transport to and from school, which was dichotomized into active (walking and cycling) and passive (motorized) modes. Children living in the second tertile of distance from school were the least sedentary during the school traveling periods $(42 \pm 10 \%$, mean \pm true between-child SD) compared to those living in the first or third distance tertiles $(47 \pm 10$ and $49 \pm 10 \%$, respectively); the differences were clear and likely substantial (90\% confidence limits $\pm 6 \%)$. Children who traveled by motorized transport were more sedentary for each of the distance tertiles (50 versus $44 \%, 46$ versus 39\%, and 54 versus $27 \%$ for first, second, and third tertiles, respectively; $90 \%$ confidence limits $\pm 7 \%$ ). In the period of 1600-1759, girls in the third distance tertile were the most sedentary. The combined effects of 1-2 km distance from school and active commuting to school contributed to least sedentary time in children.

Keywords: accelerometer, commuting, neighborhood, New Zealand, physical activity, sedentary behavior

\section{INTRODUCTION}

Walking and cycling to school are regarded as valuable opportunities for children to accumulate physical activity (1) and maintain healthy weight $(2,3)$. Aside from the physical outcomes, traveling to school by active modes provides important opportunities for children to develop confidence, navigation and local environmental awareness, risk assessment, decision making skills, and habits for lifelong participation in active travel (4). Despite these important benefits, there have been declines in the number of children actively commuting to school across many developed countries. For example, in the UK walking and cycling to school decreased from $71 \%$ in $1975 / 1976$ to $51 \%$ in 2009 , yet, the mean commute distance remained constant at 1.5 miles (5). More strikingly, US data indicate that $41 \%$ of children walked to school in 1969 and this proportion declined to $13 \%$ in 2001 (6) - despite $57 \%$ of households reporting the presence of an elementary school within 1 mile of the residence (7). Presently, the "school run" in the UK generates $\sim 20 \%$ of automobile traffic in the mornings during term time (5), causing a substantial amount of congestion on urban road networks, localized air pollution, and traffic-related injuries (8). In New Zealand, between 1989/1990 and 1997/1998, there was a doubling in the number of school children regularly driven to school (9). This prevalence increased from $45 \%$ in 1997/1998 to $58 \%$ in $2008 / 2012$ (10). In response to these trends, initiatives to increase active commuting to school have been implemented worldwide (11-17).

The overriding environmental factor linked to commuting to school is distance (17-22). The majority of studies report that students with shorter travel distance to school are more likely to walk and cycle compared to those who have longer travel distances 
(23-27). Marten and Olds (24) verified an exponential decline in children's walking and cycling as travel distance increased; 90\% of trips were walked or cycled at distances $<250 \mathrm{~m}$, decreasing to $10 \%$ at $3.2 \mathrm{~km}$. Cumulatively, this evidence suggests that schoolrelated active transport is associated with overall physical activity accumulation and other benefits for children, yet, this behavior has declined in recent decades.

Declines in children's physical activity are also noted in the "critical window," the time after school (28), where youth are more likely to choose how they spend their discretionary time. It has been observed that "technology-based sedentary behaviors" were most prevalent during these critical hours in youth aged 13-16. It was also reported that regular use of motorized transport was possibly a risk factor for reduced physical activity during those hours particularly for boys. In recent studies $(29,30)$, increases in sedentary behavior during the critical hours continue to be observed. Colley and associates (30) reported that boys accumulated most of their sedentary time after 15:00 on weekdays. Study findings also showed that prolonged bouts of sedentary behavior were positively associated with BMI and waist circumference whereby each additional $60 \mathrm{~min}$ of sedentary time was associated with a $\sim 1 \mathrm{~kg} \cdot \mathrm{m}^{-2}$ higher BMI and $\sim 3 \mathrm{~cm}$ higher waist circumference.

There is growing concern that youth in developed countries spend a large portion of their leisure time engaged in sedentary pursuits $(31,32)$. Studies in adults have shown that prolonged time engaged in sedentary behavior contributes to increased risk of all-cause mortality and cardiovascular disease mortality independent of leisure time physical activity $(33,34)$. While cardiovascular disease may not manifest until later in life, biological precursors for these diseases due to sedentarism may develop in youth (35). Several studies have reported that youth who were more sedentary on a daily basis had higher levels of systolic blood pressure, triglycerides, cholesterol, and/or glucose (3538). Yet, a recent longitudinal study that investigated changes in systolic blood pressure, triglycerides, and cholesterol levels associated with television viewing in girls from 9 to 19 years old, did not report similar relationships (39). Other studies have reported significant associations between cardiovascular risk factors with TV viewing but not other types of sedentary behavior $(38,40)$. The pioneering work by Hamilton and colleagues (41) exemplified that sedentary behavior needs to be studied separately from physical activity and that research is needed to specifically explore factors that are associated with sedentary behavior.

Since distance to school is the overriding environmental factor associated with travel mode to school and only a few studies have examined associations between active travel to school and sedentary behavior (and these have produced unequivocal findings) (42), in this study, we explore whether school commute distance is related to sedentary behavior by sex, age, and travel modality. We consider the relationships between sedentary behavior and distance, during the journey times between 0800-0859 and 1500-1559, and after school discretionary time (1600-1759). This study is the first to investigate patterning of sedentary behaviors in relation to school travel and after school time. Results can be used to inform family based and school-based interventions to improve child health.

\section{MATERIALS AND METHODS}

Data for children aged 6-12 years were drawn from the understanding relationships between activity and neighborhoods (URBAN) study, a cross-sectional study conducted in four cities (North Shore, Waitakere, Wellington, Christchurch) in New Zealand between April 2008 and August 2010 (43). The URBAN study sought to determine associations between neighborhood walkability, physical activity, and obesity in adults and children. Details of the study design, recruitment procedures, and protocol have been published elsewhere (43). Informed consent was obtained from a parent or caregiver who participated in the URBAN study. Methods and measures specific to the current investigation are presented here.

\section{NEIGHBORHOOD AND HOUSEHOLD SELECTION}

Twelve neighborhoods were selected in each city, stratified by walkability (high/low) and ethnicity (high-Māori population/lowMāori population) at the mesh-block level (geographic census unit of $\sim 100$ households) (44). Māori are the indigenous population of New Zealand (according to the Treaty of Waitangi principles of protection, participation, and partnership researchers have a responsibility to upheld these principles in research involving Māori) (45). Walkability was calculated using geographical information systems (GIS)-derived measures of street connectivity, dwelling density, retail floor area ratio, and land use mix (ArcInfo 9.1, ESRI, Redlands, CA, USA) (46). Neighborhood selection resulted in three high walkability/high Māori, three high walkability/low Māori, three low walkability/high Māori, and three low walkability/low Māori neighborhoods within each city (Table 1). Door to door methodology was employed to recruit every $n t h$

Table 1 | Number of participants and Neighborhood NDAla Total score in the three tertiles of distance from school by neighborhood type.

\begin{tabular}{|c|c|c|c|}
\hline & \multicolumn{3}{|c|}{$\begin{array}{l}\text { Street network commute distance } \\
\text { between residence and school (tertiles) }\end{array}$} \\
\hline & D1 & D2 & D3 \\
\hline \multicolumn{4}{|c|}{ Neighborhood type } \\
\hline 1 & 19 & 23 & 27 \\
\hline 2 & 34 & 40 & 37 \\
\hline 3 & 30 & 22 & 15 \\
\hline \multirow[t]{2}{*}{4} & 17 & 15 & 16 \\
\hline & \multicolumn{3}{|c|}{ Neighborhood NDAl total } \\
\hline 1 & 9 & 9 & 6 \\
\hline 2 & 9 & 10 & 10 \\
\hline 3 & 12 & 14 & 12 \\
\hline 4 & 14 & 16 & 14 \\
\hline
\end{tabular}

Distance tertiles (km): D1, 0-0.8; D2, 0.8-1.9; D3, 1.9-15.6.

Neighborhood type: 1, low walkability-low Māori; 2, low walkability-high Māori; 3, high walkability-low Māori; 4, high walkability-high Māori.

aDAl, neighborhood destination accessibility index score, which is a geographical information system score for measuring infrastructure support for neighborhood physical activity. 
household (using differential sampling rates within each neighborhood), resulting in 42 households per neighborhood. The response rate for the study was $44.8 \%$.

\section{PARTICIPANTS AND PROTOCOL}

One child per household (if the household included a child) was asked to participate following consent from their parent or caregiver. Children were included in the study provided they were between the ages of 5 and 13 years old, were not physically disabled, and they provided assent to participate. Two subsequent visits were arranged 8 days apart. During the first visit, the study was introduced, written informed consent/assent was gained, and the accelerometer and compliance log were provided to the children. Three days later, the researcher telephoned the parents to check compliance with accelerometer wear protocols. At the second visit, the researcher collected the accelerometer and compliance log, and measured participants' height and weight.

\section{MEASURES}

\section{Sedentary behavior}

Time spent being sedentary was objectively measured with the Actical accelerometer (Mini-Mitter, Sunriver, OR, USA) fitted to an elastic waistband and worn above the right hip. The units have been shown to be reliable and valid in children $(47,48)$. Prior to distribution, the units were tested for functionality and set up to record data in 30-s epochs. Participants were instructed to wear the monitors during waking hours, but remove them when participating in water-based activities and contact sports.

Actical Export File (Version 02.10) listings for each participant were read and plotted for checking using SAS (Version 9.2; SAS Institute, Cary, NC, USA). During data collection, event markers were used to monitor delivery and collection of the devices to ensure that data included for analysis belonged to the children and not the research officers when delivering and picking up the accelerometers. To check whether the accelerometers were faulty, SAS activity printouts were checked for excessive accelerometer counts accumulated during normal sleep from 0000 to 0500 hours. Data from faulty accelerometers were removed from analysis. The threshold for sedentary time was set to $<100$ counts per minute (49). To maximize data inclusion and avoid bias, as in our previous work with adults (50), we opted for a 60-min non-wear time and $10-\mathrm{h} /$ day wear time for inclusion in daily analyses, which typically results in inclusion of $\sim 85 \%$ of children with at least 4 days of valid activity data (51). Non-wear time was defined as $60 \mathrm{~min}$ or more of consecutive 0 counts $(50,52,53)$. Data collected during weekend days and school holidays were excluded. With parental assistance, children completed a compliance log for the duration of the accelerometer data collection period. Each day, participants recorded the times they rose and went to bed, times the accelerometer was removed, and activities the participant engaged in during monitor removal. Information gathered from the compliance logs assisted with confirming accelerometer data start and end times.

\section{Distance to school}

The shortest street network distance from each residential address to the relevant school was calculated using the OD Cost-Matrix function in ArcGIS Network Analyst, Version 9.2 (54). Calculated distances were then split into tertiles based on data distribution. The categorization of data into these distances aligned with previous research (27).

\section{Travel mode}

Children's mode of transport to and from school for the 7-day monitoring period was entered in a travel log by the child, with parental assistance. Travel modes were classified as passive (car or bus) or active (walk, bicycle, skateboard, scooter). Even though physical activity is accumulated before and after bus use, we included bus transport as passive in accordance with previous research $(14,15)$. For every child, travel mode before and after school on each day was accounted for in the analysis (see below).

\section{ANALYSES}

All analyses were performed with the statistical analysis system (Version 9.2, SAS Institute, Cary, NC, USA). Generalized linear mixed modeling, realized with Proc Glimmix, was used to estimate factors affecting proportion of time spent in sedentary behavior. The dependent variable was hourly observations of the number of each child's sedentary minutes (i.e., minutes in which the accelerometer count was $<100$ ), expressed as a proportion of the number of minutes of recording (up to 60) for each hour of each school day the accelerometer was worn. Each hourly observation was weighted by the number of recorded minutes. The logit link function and the binomial distribution were invoked to effectively specify logistic regression, and the fact that individual sedentary minutes were not independent was taken into account by estimating an over-dispersion factor. The resulting distribution of the dependent variable is called pseudo-Bernoulli (see Example 38.1 in the Proc Glimmix documentation). The fixed effects in the mixed model included main effects to adjust to the mean levels of city (four levels), maximum daily temperature (simple numeric), and sex (two levels). Hour of the day was a main effect with levels chosen that was appropriate to the periods of the day being analyzed (0800-0859 and 1500-1559 or 1600-1759 hours). Distance from school was a nominal predictor with levels representing the tertiles of commute distance. Tertiles are a user-friendly way to present or analyze continuous variables (e.g., distance) (55). This practice also circumvents the assumption of a linear relation between the variable and the outcome of interest (55). Interactions between commute distance and travel mode (active, passive), age, sex, and individual built environment features by age were examined to provide relevant means. Random model effects were the child, the interaction of the child with before or after school periods for sedentary time and with the day of the week to account for the levels of repeated measurement on each child. The residual was specified in a manner that estimated the over-dispersion factor. Random effects and the over-dispersion factor were combined to provide between-child SD for sedentary behavior for each hour of the day.

Inferences about effects were based on probabilities of substantial magnitudes of the true values of the effects (56). Inferences were mechanistic, that is, an effect was declared "unclear" if the $90 \%$ confidence interval included substantial positive and negative values (i.e., wide confidence interval). All other effects were declared clear and are shown as the observed magnitude, with a 
qualitative probability of that magnitude. The descriptors used were $<1 \%$, almost certainly not; $1-5 \%$, very unlikely; 6-25\%, unlikely; 26-75\%, possibly; 76-95\%, likely; 96-99\%, very likely; $>99 \%$, almost certainly (56). The way to interpret the findings is as follows: if the result is followed with a descriptor of "likely", it means that there is a $76-95 \%$ chance that the true value of the statistic is practically important. The same approach can be used for the rest of the descriptors.

The threshold for substantial effects was based initially on standardization: 0.20 of the pure between-child SD derived from the child random effect in the mixed model (56). For percent of time spent in sedentary behavior, 0.20 of this SD was 2.8 (where the mean percent of each hour spent sedentary was $\sim 50$ ). We opted for a smallest important effect of $5 \%$ of the hour, representing $\sim 10 \%$ of total sedentary time (57).

\section{RESULTS}

Two hundred and sixty eight children fulfilled the accelerometer requirements (as described above) and their data were retained for analyses (Table 2). The ethnic composition of the sample was 23\% Māori/Polynesian, 12\% Asian, and 65\% European/Other ethnic descent. The number of participants who contributed data for analysis by hours of interest is as follows: 0800-0859, 1500-1559, $1600-1659, n=222 ; 1700-1759, n=221$. Different participants contributed to the total number $(n)$ per hour of interest. There were trivial differences between boys and girls in age, BMI, and distance lived from school. Travel mode data were provided by $98 \%$ of participants. The remaining $2 \%$ of data belonged to children who were absent from school due to illness but continued to wear accelerometers.

Children's sedentary times an hour before (0800-0859) and after school (1500-1559) combined, and after school discretionary time (1600-1759) by distance from school (tertiles) are presented in Table 3. Overall, in the hours before and after school, children who lived in the second tertile of distance from school accumulated the least amount of sedentary time compared to children in the

Table 2 | Descriptive characteristics (mean \pm SD) of study participants $(n=268)$.

\begin{tabular}{lcc}
\hline Tertiles & Female & Male \\
\hline Age (y) & & \\
1 & $6.8 \pm 0.9$ & $6.8 \pm 0.9$ \\
2 & $9.2 \pm 0.7$ & $9.4 \pm 0.6$ \\
3 & $11.8 \pm 0.6$ & $11.7 \pm 0.7$ \\
BMI (kg $\mathbf{m}^{-\mathbf{2})}$ & & \\
1 & $15.4 \pm 0.8$ & $15.1 \pm 1.2$ \\
2 & $17.3 \pm 0.8$ & $17.3 \pm 0.8$ \\
3 & $22.5 \pm 4.3$ & $22.0 \pm 3.2$ \\
School distance (m) & & \\
1 & $530 \pm 320$ & $1300 \pm 260$ \\
2 & $1400 \pm 500$ & $4400 \pm 3300$ \\
3 & $4200 \pm 2200$ & \\
\hline
\end{tabular}

y, years; $B M I$, body mass index. first and third tertiles. However, girls who lived closest to school spent the least amount of time being sedentary, while for boys this was true if they lived in the third distance tertile from school. Children who lived in the second tertile of distance from school accumulated the least amount of sedentary time, irrespective of travel mode.

During the after school discretionary time (1600-1759), the least amount of sedentary time was accumulated in children in the first and second age tertiles (Table 3 ). The greatest proportion of sedentary time was accumulated in the oldest children living the furthest from school. Girls living in the first tertile of distance, and boys living in the third tertile of distance were least sedentary.

Analysis of the differences in the proportion of time spent sedentary between distance tertiles by age and sex tertiles, and mode of transport are presented in Table 4. Values are presented as chances with a qualitative label, describing whether the true value of the statistic was practically important. The effects with the qualitative descriptors of "likely" and "very likely" ("almost certainly" was not observed) are used to identify practically important effects. For males and children in the first age tertile (youngest), during the period before and after school traveling time, the difference in sedentary time between the second and first tertiles of distance was likely to be important $(-8.0 \pm 9.4 \% \mathrm{CL}$ and $-8.3 \pm 10 \% \mathrm{CL}$, respectively). For children in the first age tertile, the difference

Table 3 | Percentage of time children spent sedentary (mean \pm SD) during school travel periods and after school periods for three tertiles of distance from school and for subgroups of sex, age, and mode of transport.

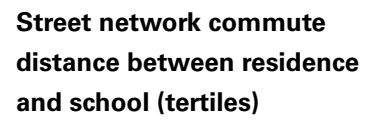

Distance tertiles (km): 1, 0-0.8; 2, 0.9-1.9; 3, 2.0-15.6.

Age tertiles (y): 1, 5.1-8.1; 2, 8.2-10.5; 3, 10.6-13.0.

Active: walking and cycling. Passive: motorized transport.

Bold: greatest proportion of sedentary time. 
Table 4 | Changes in percent mean sedentary time during school travel periods and after school periods for school distance by sex, age tertiles, and mode of transport ${ }^{\mathrm{a}}$

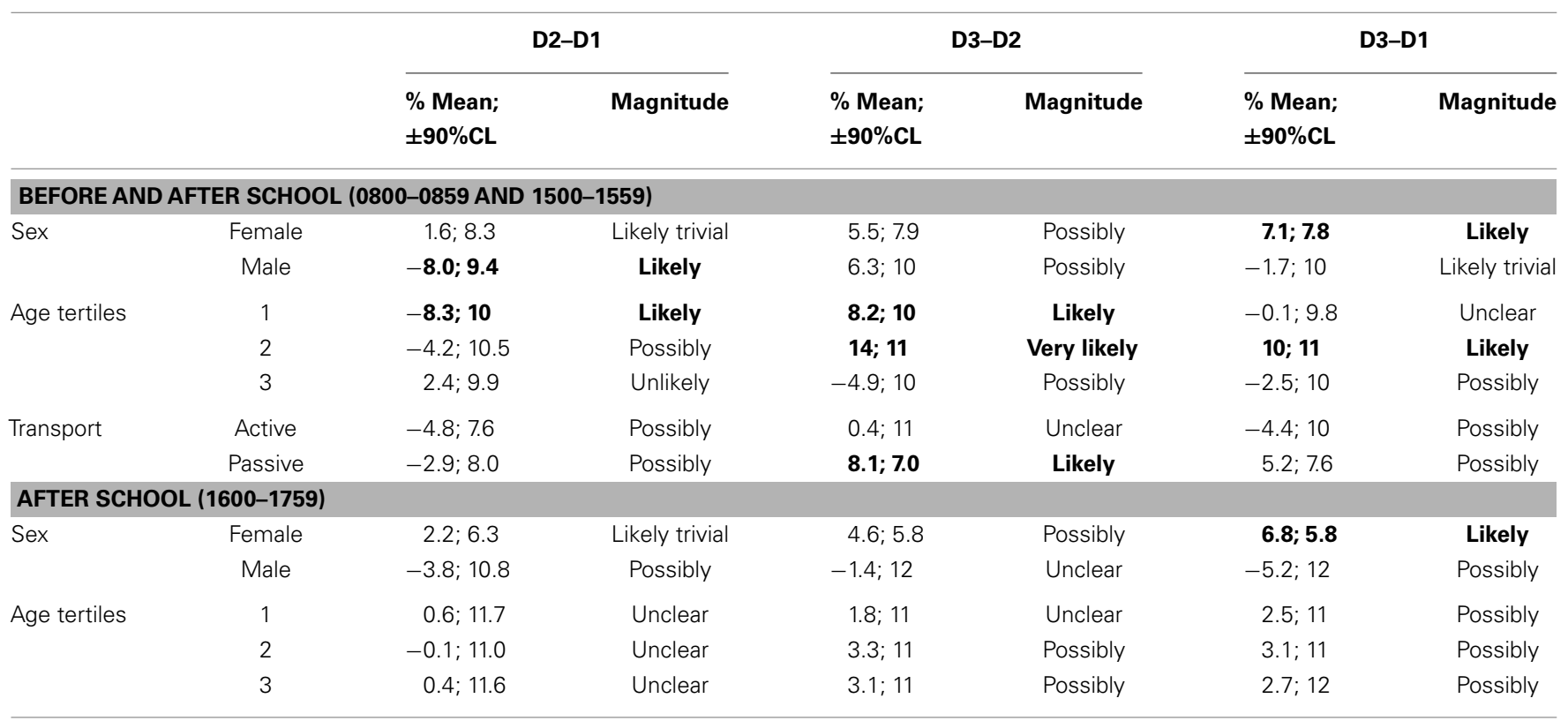

Distance tertiles (km): 1, 0-0.8; 2, 0.9-1.9; 3, 2.0-15.6.

Age tertiles (y): 1, 5.1-8.1; 2, 8.2-10.5; 3, 10.6-13.0.

Active: walking and cycling. Passive: motorized transport.

Bold: greatest proportion of sedentary time.

Chances of the true effect: <1\%, almost certainly not; 1-5\%, very unlikely; 6-25\%, unlikely; 26-75\%, possibly; 76-95\%, likely; 96-99\%, very likely; >99\%, almost certainly.

${ }^{a}$ Data are percent mean change in the proportion of time spent sedentary Before and after school (0800-0859 and 1500-1559) and After school (1600-1759); 90\% confidence limits $( \pm C L$ ) between distance tertiles (D2 minus D1; D3 minus D2; D3 minus D1), and the probabilistic inference about the true magnitude of change.

between third and second tertiles of distance was also important $(8.2 \pm 9.4 \% \mathrm{CL})$. The greatest difference in percent mean sedentary time, which was "very likely" to be important, was observed for children in the second age tertile for comparisons between the third and second tertile of distance. The only "likely" difference observed in the period of 1600-2000 was for girls between the third and first tertile.

\section{DISCUSSION}

This is the first study to examine distance to school, and objectively measured sedentary time by travel mode in children. Overall, the combined effects of residing 1-2 km distance from school and actively commuting to school contributed to least sedentary time in children. Similarly, Faulkner and colleagues (58) observed a strong association between children's active travel (boys in particular) residing at a distance between 1000 and $1600 \mathrm{~m}$ from school irrespective of neighborhood type. In this study, there was also a trend toward children residing in the second distance tertile from school being substantially less sedentary than other children, implying a non-linear relationship between school travel and sedentary behavior.

A non-linear relationship between distance to school and sedentary time indicates that other factors are mediating the overall relationship. Living further away from school may contribute toward more time getting to and from school actively leaving less time to engage in sedentary activities. There are several aspects (25) that could be mediating this relationship including specific built environment characteristics $(59,60$, McGrath et al., under review), walkability around schools, and ongoing school-related active commuting initiatives (11-16).

In this study, there was a strong influence of age. Those children in the third age tertile, living in the first and second distance tertiles from school were the most sedentary. Since in 9-13-year-old children, most of the sedentary behavior occurs at home (61), a short distance to school may mean that children get home from school in a short amount of time and then spend the rest of the time engaging in sedentary activities (e.g., watching television or playing video games). During the critical hours after school, children in the third age tertile were the most sedentary. As children tend to be granted more freedom to roam and determine their leisure time activities in later years (62), they may at this age choose sedentary activities over physical activities. Gorely and colleagues (63) showed that when adolescents did not participate in active travel, they did not compensate with different physical activities, but rather filled their leisure time by engaging in technology-based and social sedentary behaviors.

Earlier research has shown that children living closer to school were more likely to engage in active travel to school $(25,27$, $62,64,65)$ or access their local school playground after school 
(66-68). We inferred that children living closest to school (first tertile of distance) may therefore engage in less sedentary behaviors before or after school. However, our data suggested that when sedentary behavior was investigated in the hours before and after school, living a distance of less than $\sim 0.8 \mathrm{~km}$ (first tertile of distance) was associated with a greater proportion of time spent sedentary before and after school (particularly for boys and younger children).

Previous studies have consistently shown that boys were more active than girls and those boys engage better with active transport $(3,58,69,70)$. In our study, even though we did not investigate distance by sex and by travel mode, we observed that girls accumulated the least sedentary time living in neighborhoods $<1.9 \mathrm{~km}$ from school. As expected, those who lived furthest away and passively commuted were the most sedentary.

Distance to school is only one of the many factors that children and parents consider or are influenced by when making decisions about travel $(27,71)$ or play. There are several other contextual issues (25) that could be mediating these relationships including siblings and parental modeling. King and associates (72) identified that maternal age and parental modeling were significant correlates of sedentary behavior and not physical activity. They speculated that these correlates may have been a reflection of a decreased activity in older mothers or parental occupation with younger children, resulting in more sedentary behaviors. Other factors that may be equally important include perceptions of unsafe neighborhoods and social disorder, road traffic safety, family transport choices/options, parental attitudes, social/cultural norms, socio-demographics, walkability around schools, and lack or presence of school-related active commuting initiatives (11-16). Molnar and colleagues (73) assessed social disorder in neighborhoods using videotapes of over 15,000 block faces, and saw significant negative associations between social disorder and physical activity in youth (73). Similarly, parental anxiety about neighborhood safety has been associated with reduced physical activity in inner city children (74). Interestingly, in a national sample of mothers of preschool children, it was reported that mothers' perception of unsafe neighborhoods was related to increased children's TV watching but no relationship was found for perceived safety and outdoor play time (75). In a relevant review (76), road safety and "stranger danger" were identified as the main parental concerns relative to children's safety. Consequently, parents may restrict outdoor play in the neighborhood irrespective of distance to play facilities or school. In addition, social norms of being a "responsible" parent may also play a role in the choices made regarding driving children to school (76). These choices coupled with car availability may impact on whether children actively commute to school or play facilities.

Strengths of the present study include the objective measurement of sedentary time and distance to school, and the robust sampling approach. Even though the response rate was $45 \%$, it is higher than other similar studies with adults [e.g., $26.0 \%$ (77), 11.5\% (78)] and children and adolescents [27\% (79), 44\% (80)]. Every effort was undertaken to ensure a good response rate (81) (e.g., face-to-face recruitment, low-participant burden, no invasive procedures, practically no risk for the children to participate in the study, a draw for a trip away was offered to parents, a report of the child's data was provided to parents after the study and other strategies employed to improve recruitment and participation). According to Galea and colleagues (82), a low-response rate, non-participation bias or non-response bias, does not necessarily mean that there will be bias fundamental to the study. The cross-sectional nature of the study means that causal relationships cannot be established. When analyzing continuous variables, it is often useful to use tertile analysis where participants are separated into equal groups. However, threshold values for the tertiles are often not exact (equal portioning) and sometimes varying the thresholds slightly can change the results.

\section{CONCLUSION}

The combined effects of $1-2 \mathrm{~km}$ distance from school and active commuting to school contributed to least sedentary time in children. Many children could benefit from after-school activities to reduce sedentary time during the weekdays, and those living furthest or closest from school may have the greatest need. Planners and policy makers may take this new information into account when considering location when building new schools or closing down existing schools (83-86), but caution is warranted due to the confounding factors that may have not been accounted for in this analysis. Understanding the local environment from the sedentary behavior perspective, in addition to evidence from physical activity research, is critical in the efforts to increase physical activity and increase health benefits that accumulate into adulthood. The findings can provide the basis for future sedentary behavior research.

\section{AUTHOR CONTRIBUTIONS}

Erica A. Hinckson developed the first draft of the manuscript. Melody Oliver and Hannah Badland contributed to the first draft of the manuscript introduction. Erica A. Hinckson, Karen Witten, Suzanne Mavoa, Hannah Badland, and Robin A. Kearns contributed to the conception and the design of the study. Erica A. Hinckson, Les McGrath, Hannah Badland, and Melody Oliver managed the data collection and database. Will Hopkins analyzed data. Erica A. Hinckson and Les McGrath contributed to data cleaning and analysis. All authors provided feedback during manuscript development. Each author has read and approved the final manuscript.

\section{ACKNOWLEDGMENTS}

The study was funded by the Health Research Council of New Zealand (grant 07/356). At the time of study design and data collection, National Heart Foundation New Zealand Research Fellowships supported Hannah Badland and Melody Oliver. Les McGrath was supported by a Health Research Council of New Zealand Ph.D. scholarship. The funding bodies were not involved in the design, conduct, data collection, management, or publication of the study. The authors also gratefully acknowledge the children who participated in the study, research assistants who collected the data, and territorial authorities for providing the GIS datasets. 


\section{REFERENCES}

1. Cooper A, Andersen LB, Wedderkopp N, Page AS, Froberg K. Physical activity levels of children who walk, cycle, or are driven to school. Am J Prev Med (2005) 29(3):179-84. doi:10.1016/j.amepre.2005.05.009

2. Gordon-Larsen P, Nelson MC, Beam K. Associations among active transportation, physical activity, and weight status in young adults. Obes Res (2012) 13(5):868-75. doi:10.1038/oby.2005.100

3. Rosenberg DE, Sallis JF, Conway TL, Cain KL, McKenzie TL. Active transportation to school over 2 years in relation to weight status and physical activity. Obesity (2012) 14(10):1771-6. doi:10.1038/oby.2006.204

4. Rissotto A, Tonucci F. Freedom of movement and environmental knowledge in elementary school children. J Env Phychol (2002) 22(1-2):65-77. doi:10.1006/jevp.2002.0243

5. Department for Transport. National Travel Survey. London: Department for Transport (2010).

6. McDonald NC. Active transportation to school: trends among U.S. schoolchildren, 1969-2001. Am J Prev Med (2007) 32(6):509-16. doi:10.1016/j. amepre.2007.02.022

7. Brownson RC, Boehmer TK. Patterns and Trends in Physical Activity, Occupation, Transportation, Land Use and Sedentary Behaviors. Saint Louis: Transportation Research Board Special Report 282 (2004).

8. Cooper AR, Wedderkopp N, Jago R, Kristensen PL, Moller NC, Froberg K, et al. Longitudal associations of cycling to school with adolescent fitness. Prev Med (2008) 47(3):324-8. doi:10.1016/j.ypmed.2008.06.009

9. Ministry of Transport. Household Travel Survey: Comparing Travel Modes. Wellington: Ministry of Transport (2008).

10. Ministry of Transport. Household Travel Survey: Comparing Travel Modes. Wellington: Ministry of Transport (2013).

11. Stopher P, Zhang Y, Zhang J, Halling B. Results of an evaluation of TravelSmart in South Australia. Proceedings of the 32nd Australasian Transport Research Forum (ATRF) (2009). Available from: http://www.atrf.info/papers/2009/2009_ Stopher_Zhang_Zhang_Halling.pdf

12. Boarnet MG, Anderson CL, Day K, McMillan T, Alfonzo M. Evaluation of the California Safe Routes to School legislation: Urban form changes and children's active transportation to school. Am J Prev Med (2005) 28(2S2):134-40. doi:10.1016/j.amepre.2004.10.026

13. Boarnet MG, Day K, Anderson C, McMillan T, Alfonzo M. California’s safe routes to school program: impacts on walking, bicycling, and pedestrian safety. J Am Plann Assoc (2005) 71(3):301-17. doi:10.1080/01944360508976700

14. Hinckson EA, Garrett N, Duncan JS. Active commuting to school in New Zealand Children (2004-2008): a quantitative analysis. Prev Med (2011) 52:332-6. doi:10.1016/j.ypmed.2011.02.010

15. Mammen G, Stone MR, Faulkner G, Ramanathan S, Buliung R, O'Brien C, et al. Active school travel: an evaluation of the Canadian school travel planning intervention. Prev Med (2013) 60:55-9. doi:10.1016/j.ypmed.2013.12.008

16. Cooper J, McMillan T. Safe Routes to School Local School Project: A Health Evaluation at 10 Low-Income Schools. Berkeley, CA: UC Berkeley Safe Transportation Research and Education Center Contract No.: SafeTREC Report Number: UCB-ITS-SAFETREC-2010-1 (2010). Available from: http://www.safetrec. berkeley.edu

17. Wen LM, Fry D, Merom D, Rissel C, Dirkis H, Balafas A. Increasing active travel to school: are we on the right track? A cluster randomised controlled trial from Sydney, Australia. Prev Med (2008) 47(6):612-8. doi:10.1016/j.ypmed. 2008.09.002

18. Oliver M, Schofield G. Childhood obesity, physical activity, and the physical environment. In: Pearce J, Witten K, editors. Geographies of Obesity: Environmental Understandings of the Obesity Epidemic. Aldershot: Ashgate Publishing (2010). p. 175-206.

19. Oliver M, Badland H, Mavoa S, Witten K, Kearns R, Ellaway A, et al. Environmental and socio-demographic associates of children's active transport to school: a cross-sectional investigation from the URBAN study. Int J Behav Nutr Phys Act (2014) 11:70. doi:10.1186/1479-5868-11-70

20. Su JG, Jerrett M, McConnell R, Berhane K, Dunton G, Shankardass K, et al. Factors influencing whether children walk to school. Health Place (2013) 22:153-61. doi:10.1016/j.healthplace.2013.03.011

21. Centers for Disease Control Prevention. Barriers to children walking to or from school: United States, 2004. MMWR Morb Mortal Wkly Rep (2005) 54:949-52.

22. D'Haese S, De Meester F, De Bourdeaudhuij I, Deforche B, Cardon G. Criterion distances and environmental correlates of active commuting to school in children. Int J Behav Nutr Phys Act (2011) 8:88. doi:10.1186/14795868-8-88

23. Ewing R, Schroeer W, Greene W. School location and student travel: analysis factors affecting mode choice. J Transport Res Board (2004) 1895:55-63. doi:10.3141/1895-08

24. Marten N, Olds T. Physical activity: patterns of active transport in 11-12 year old Australian children. Aust N Z J Public Health (2004) 28(2):167-72. doi:10.1111/j.1467-842X.2004.tb00931.x

25. McMillan TE. The relative influence of urban form on a child's travel mode to school. Transport Res A (2007) 41(1):69-79.

26. Davison KK, Werder JL, Lawson CT. Children's active commuting to school: current knowledge and future directions. Prev Chronic Dis (2008) 5(3):A100.

27. Schlossberg M, Greene J, Phillips PP, Johnson B, Parker B. School trips: effects of urban form and distance on travel mode. J Am Plann Assoc (2006) 72(3):337-46. doi:10.1080/01944360608976755

28. Atkin AJ, Gorely T, Biddle S, Marshall SJ, Cameron N. Critical hours: physical activity and sedentary behavior of adolescents after school. Pediatr Exerc Sci (2008) 20(4):446-56.

29. Arundell L, Ridgers ND, Veitch J, Salmon J, Hinkley T, Timperio A. 5-Year changes in afterschool physical activity and sedentary behavior. Am J Prev Med (2013) 44(6):605-11. doi:10.1016/j.amepre.2013.01.029

30. Colley RC, Garriguet D, Janssen I, Wong SL, Saunders TJ, Carson V, et al. The association between accelerometer-measured patterns of sedentary time and health risk in children and youth: results from the Canadian health measures survey. BMC Public Health (2013) 13(1):200. doi:10.1186/1471-2458-13-200

31. Leatherdale ST, Faulkner G, Arbour-Nicitopoulos K. School and student characteristics associated with screen-time sedentary behavior among students in grades 5-8, Ontario, Canada, 2007-2008. Prev Chronic Dis (2010) 7(6):122-8.

32. Centers for Disease Control and Prevention. Youth risk behavior surveillance United States, 2011. MMWR Surveill Summ (2012) 61(SS-4):161-2.

33. Katzmarzyk PT, Church TS, Craig CL, Bouchard C. Sitting time and mortality from all causes, cardiovascular disease, and cancer. Med Sci Sports Exerc (2009) 41(5):998. doi:10.1249/MSS.0b013e3181930355

34. Dunstan DW, Barr ELM, Healy GN, Salmon J, Shaw JE, Balkau B, et al. Television viewing time and mortality: the Australian diabetes, obesity and lifestyle study (AusDiab). Circulation (2010) 121(3):384-91. doi:10.1161/ CIRCULATIONAHA.109.894824

35. Martínez-Gómez D, Eisenmann JC, Gómez-Martínez S, Veses A, Marcos A, Veiga OL. Sedentary behavior, adiposity, and cardiovascular risk factors in adolescents. The AFINOS study. Rev Esp Cardiol (2010) 63(3):277-85. doi:10.1016/S18855857(10)70060-8

36. Ekelund U, Anderssen S, Froberg K, Sardinha LB, Andersen LB, Brage S. Independent associations of physical activity and cardiorespiratory fitness with metabolic risk factors in children: the European youth heart study. Diabetologia (2007) 50(9):1832-40. doi:10.1007/s00125-007-0762-5

37. Sardinha LB, Andersen LB, Anderssen SA, Quitério AL, Ornelas R, Froberg K, et al. Objectively measured time spent sedentary is associated with insulin resistance independent of overall and central body fat in 9-to 10-year-old Portuguese children. Diabetes Care (2008) 31(3):569-75. doi:10.2337/dc07-1286

38. Chaput J-P, Saunders TJ, Mathieu ME, Henderson M, Tremblay MS, O'Loughlin $\mathrm{J}$, et al. Combined associations between moderate to vigorous physical activity and sedentary behaviour with cardiometabolic risk factors in children. Appl Physiol Nutr Metab (2013) 38(5):477-83. doi:10.1139/apnm2012-0382

39. Mitchell JA, Pate RR, Liese AD. Changes in cardiovascular disease risk factors from age 9 to 19 and the influence of television viewing. Obesity (2013) 21(2):386-93. doi:10.1002/oby.20014

40. Stamatakis E, Coombs N, Jago R, Gama A, Mourão I, Nogueira H, et al. Typespecific screen time associations with cardiovascular risk markers in children. Am J Prev Med (2013) 44(5):481-8. doi:10.1016/j.amepre.2013.01.020

41. Hamilton MT, Healy GN, Dunstan DW, Zedric TW, Owen N. Too little exercise and too much sitting: Inactivity physiology and the need for new recommendations on sedentary behavior. Curr Cardiovasc Risk Rep (2008) 2(4):292-8. doi:10.1007/s12170-008-0054-8

42. Schoeppe S, Duncan MJ, Badland H, Oliver M, Curtis C. Associations of children's independent mobility and active travel with physical activity, sedentary behaviour and weight status: a systematic review. J Sci Med Sport (2013) 16(4):312-9. doi:10.1016/j.jsams.2012.11.001 
43. Badland HM, Schofield GM, Witten K, Schluter PJ, Mavoa S, Kearns RA, et al. Understanding the Relationship between Activity and Neighbourhoods (URBAN) Study: research design and methodology. BMC Public Health (2009) 9(1):224. doi:10.1186/1471-2458-9-224

44. Statistics New Zealand. Census 2006. Wellington: Statistics New Zealand (2006).

45. Health Research Council of New Zealand. Te Ara Tika Guidelines for Māori Research Ethics: A Framework for Researchers and Ethics Committee Members. Auckland: Health Research Council of New Zealand (2010).

46. Leslie E, Coffee N, Frank L, Owen N, Bauman A, Hugo G. Walkability of local communities: using geographic information systems to objectively assess relevant environmental attributes. Health Place (2007) 13(1):111-22. doi:10.1016/j.healthplace.2005.11.001

47. Esliger DW, Tremblay MS. Technical reliability assessment of three accelerometer models in a mechanical setup. Med Sci Sports Exerc (2006) 38(12):2173. doi:10.1249/01.mss.0000239394.55461.08

48. Esliger DW, Probert A, Gorber SC, Bryan S, Laviolette M, Tremblay MS. Validity of the actical accelerometer step-count function. Med Sci Sports Exerc (2007) 39(7):1200. doi:10.1249/mss.0b013e3804ec4e9

49. Puyau M, Adolph A, Vohra F, Zakeri I, Butte N. Prediction of activity energy expenditure using accelerometers in children. Med Sci Sports Exerc (2004) 36:1625-31.

50. Witten K, Blakely T, Bagheri N, Badland H, Ivory V, Pearce J, et al. Neighborhood built environment and transport and leisure physical activity: findings using objective exposure and outcome measures in New Zealand. Environ Health Perspect (2012) 120(7):971-7. doi:10.1289/ehp.1104584

51. Colley R, Gorber SC, Tremblay MS. Quality control and data reduction procedures for accelerometry-derived measures of physical activity. Health Rep (2010) 21(1):1-7.

52. Van Dyck D, Cardon G, Deforche B, Owen N, Sallis JF, De Bourdeaudhuij I. Neighborhood walkability and sedentary time in Belgian adults. Am J Prev Med (2010) 39(1):25-32. doi:10.1016/j.amepre.2010.03.004

53. Oliver M, Badland HM, Schofield GM, Shepherd J. Identification of accelerometer nonwear time and sedentary behavior. Res Q Exerc Sport (2011) 82(4):779-83. doi:10.1080/02701367.2011.10599814

54. Mavoa S, Witten K, Pearce J, Day P. Measuring Neighbourhood Walkability in New Zealand Cities. Auckland: Centre for Social and Health Outcomes Research and Evaluation, Massey University (2009).

55. Altman DG, Bland JM. Statistics notes: quartiles, quintiles, centiles, and other quantiles. BMJ (1994) 309(6960):996. doi:10.1136/bmj.309.6960.996

56. Hopkins WG, Marshall SW, Batterham AM, Hanin J. Progressive statistics for studies in sports medicine and exercise science. Med Sci Sports Exerc (2009) 41(1):3. doi:10.1249/MSS.0b013e31818cb278

57. Hinckson EA, Hopkins WG, Aminian S, Ross K. Week-to-week differences of children's habitual activity and postural allocation as measured by the ActivPAL monitor. Gait Posture (2013) 38:663-7. doi:10.1016/j.gaitpost.2013. 02.013

58. Faulkner G, Stone M, Buliung R, Wong B, Mitra R. School travel and children's physical activity: a cross-sectional study examining the influence of distance. BMC Public Health (2013) 13(1):1166. doi:10.1186/1471-2458-13-1166

59. Van Dyck D, Cardon G, Deforche B, De Bourdeaudhuij I. Lower neighbourhood walkability and longer distance to school are related to physical activity in Belgian adolescents. Prev Med (2009) 48(6):516-8. doi:10.1016/j.ypmed. 2009.03.005

60. Carver A, Timperio A, Hesketh K, Crawford D. Are safety-related features of the road environment associated with smaller declines in physical activity among youth? J Urban Health (2009) 87(1):29-43. doi:10.1007/s11524-0099402-3

61. Liao Y, Intille S, Wolch J, Pentz M, Dunton G. Understanding the physical and social contexts of children's non-school sedentary behavior: an ecological momentary assessment study. J Phys Act Health (2014) 11:588-95. doi:10.1123/jpah.2011-0363

62. Merom D, Tudor-Locke C, Bauman A, Rissel C. Active commuting to school among NSW primary school children: implications for public health. Health Place (2006) 12:678-87. doi:10.1016/j.healthplace.2005.09.003

63. Gorely T, Biddle S, Marshall S, Cameron N, Cassey L. The association between distance to school, physical activity and sedentary behaviors in adolescents: project STIL. Pediatr Exerc Sci (2009) 21(4):450.

64. Timperio A, Ball K, Salmon J, Roberts R, Giles-Corti B, Simmons D, et al. Personal, family, social, and environmental correlates of active commuting to school. Am J Prev Med (2006) 30(1):45-51. doi:10.1016/j.amepre. 2005.08.047

65. Timperio A, Crawford D, Telford A, Salmon J. Perceptions about the local neighbourhood and walking and cycling among children. Prev Med (2004) 38:39-47. doi:10.1016/j.ypmed.2003.09.026

66. Wechsler H, Devereaux RS, Davis M, Collins J. Using the school environment to promote physical activity and healthy eating. Prev Med (2000) 31(2):S121-37. doi:10.1006/pmed.2000.0649

67. Grow HM, Saelens BE, Kerr J, Durant NH, Norman GJ, Sallis JF. Where are youth active? Roles of proximity, active transport, and built environment. Med Sci Sports Exerc (2008) 40(12):2071. doi:10.1249/MSS.0b013e3181817baa

68. Roemmich JN, Epstein LH, Raja S, Yin L, Robinson J, Winiewicz D. Association of access to parks and recreational facilities with the physical activity of young children. Prev Med (2006) 43(6):437-41. doi:10.1016/j.ypmed.2006. 07.007

69. Kettner S, Kobel S, Fischbach N, Drenowatz C, Dreyhaupt J, Wirt T, et al. Objectively determined physical activity levels of primary school children in southwest Germany. BMC Public Health (2013) 13(1):895. doi:10.1186/1471-245813-895

70. Cooper AR, Page AS, Foster LJ, Qahwaji D. Commuting to school: are children who walk more physically active? Am J Prev Med (2003) 25(4):273-6. doi:10.1016/S0749-3797(03)00205-8

71. Oliver M, Badland H, Mavoa S, Witten K, Kearns R, Ellaway A, et al. Environmental and socio-demographic associates of children's active transport to school: a cross-sectional investigation from the URBAN study. Int J Behav Nutr Phys Act (2014) 11(1):70. doi:10.1186/1479-5868-11-70

72. King AC, Parkinson KN, Adamson AJ, Murray L, Besson H, Reilly JJ, et al. Correlates of objectively measured physical activity and sedentary behaviour in English children. Eur J Public Health (2011) 21(4):424-31. doi:10.1093/eurpub/ ckq104

73. Molnar BE, Gortmaker SL, Bull FC, Buka SL. Unsafe to play? Neighborhood disorder and lack of safety predict reduced physical activity among urban children and adolescents. Am J Health Promot (2004) 18(5):378-86. doi:10.4278/0890-1171-18.5.378

74. Weir LA, Etelson D, Brand DA. Parents' perceptions of neighborhood safety and children's physical activity. Prev Med (2006) 43(3):212-7. doi:10.1016/j.ypmed. 2006.03.024

75. Burdette HL, Whitaker RC. A national study of neighborhood safety, outdoor play, television viewing, and obesity in preschool children. Pediatrics (2005) 116(3):657-62. doi:10.1542/peds.2004-2443

76. Carver A, Timperio A, Crawford D. Playing it safe: the influence of neighbourhood safety on children's physical activity - a review. Health Place (2008) 14(2):217-27. doi:10.1016/j.healthplace.2007.06.004

77. Frank LD, Sallis JF, Saelens BE, Leary L, Cain K, Conway TL, et al. The development of a walkability index: application to the neighborhood quality of life study. Br J Sports Med (2010) 44(13):924-33. doi:10.1136/bjsm.2009. 058701

78. Owen N, Cerin E, Leslie E, dutoit L, Coffee N, Frank LD, et al. Neighborhood walkability and the walking behavior of Australian adults. Am J Prev Med (2007) 33(5):387-95. doi:10.1016/j.amepre.2007.07.025

79. Carver A, Timperio AF, Crawford DA. Neighborhood road environments and physical activity among youth: the CLAN study. J Urban Health (2008) 85(4):532-44. doi:10.1007/s11524-008-9284-9

80. Prins RRG, Ball K, Timperio A, Salmon J, Oenema A, Brug J, et al. Associations between availability of facilities within three different neighbourhood buffer sizes and objectively assessed physical activity in adolescents. Health Place (2011) 17(6):1228-34. doi:10.1016/j.healthplace.2011.07.012

81. Schoeppe S, Oliver M, Badland HM, Burke M, Duncan MJ. Recruitment and retention of children in behavioral health risk factor studies: REACH strategies. Int J Behav Med (2013) 20:1-10.

82. Galea S, Tracy M. Participation rates in epidemiologic studies. Ann Epidemiol (2007) 17(9):643-53. doi:10.1016/j.annepidem.2007.03.013

83. Kearns RA, Lewis N, McCreanor T, Witten K. 'The status quo is not an option': community impacts of school closure in South Taranaki, New Zealand. J Rural Stud (2009) 25(1):131-40. doi:10.1016/j.jrurstud.2008.08.002

84. Witten K, Kearns R, Lewis N, Coster H, McCreanor T. Educational restructuring from a community viewpoint: a case study of school closure from Invercargill, New Zealand. Environ Plann C Govern Pol (2003) 21(2):203-24. doi: $10.1068 / \mathrm{c} 05 \mathrm{r}$ 
85. Witten K, McCreanor T, Kearns R. The place of schools in parents' community belonging. $N Z$ Geog (2007) 63(2):141-8. doi:10.1111/j.1745-7939.2007. 00097.x

86. Witten K, McCreanor T, Kearns R, Ramasubramanian L. The impacts of a school closure on neighbourhood social cohesion: narratives from Invercargill, New Zealand. Health Place (2001) 7(4):307-17. doi:10.1016/S1353-8292(01)00023-5

Conflict of Interest Statement: The authors declare that the research was conducted in the absence of any commercial or financial relationships that could be construed as a potential conflict of interest.

Received: 16 May 2014; accepted: 05 September 2014; published online: 23 September 2014.
Citation: Hinckson EA, McGrath L, Hopkins W, Oliver M, Badland H, Mavoa S, Witten $K$ and Kearns RA (2014) Distance to school is associated with sedentary time in children: findings from the URBAN study. Front. Public Health 2:151. doi: 10.3389/fpubh.2014.00151

This article was submitted to Child Health and Human Development, a section of the journal Frontiers in Public Health.

Copyright (C) 2014 Hinckson, McGrath, Hopkins, Oliver, Badland, Mavoa, Witten and Kearns. This is an open-access article distributed under the terms of the Creative Commons Attribution License (CC BY). The use, distribution or reproduction in other forums is permitted, provided the original author(s) or licensor are credited and that the original publication in this journal is cited, in accordance with accepted academic practice. No use, distribution or reproduction is permitted which does not comply with these terms. 